\title{
Kooperation FMH Inkasso Services AG mit Inkassostelle Encath AG in Biel
}

Im März 2006 begann die Kooperation zwischen FMH Inkasso Services AG (FIS) und der Inkassostelle Encath AG (INKAS / Inkassostelle für Ärzte und Zahnärzte). Unser Entscheid wurde von den Ärztinnen und Ärzten positiv aufgenommen. Der Kundenzuwachs ist sehr erfreulich. Dank dem Zusammenschluss der beiden operativen Einheiten am Sitz der INKAS in Biel seit Mai 2006 werden sämtliche Kunden von einem Standort betreut und die Synergien können optimal genutzt werden.

\section{Neues Geschäftsmodell und Konditionen}

Die Reaktionen unserer «ehemaligen» FIS-Kunden waren durchwegs positiv. Die attraktiven neuen Konditionen werden sehr geschätzt. Das Kostenrisiko ist neu für den Auftraggeber auf ein Minimum reduziert und identisch mit den Kosten einer Eigenlösung. Der passwortgeschützte Onlinezugriff über «my.inkas.ch» auf die laufenden und bereits verarbeiteten Inkassofälle wird rege genutzt.

\section{Neue Büroräumlichkeiten}

Mit dem Zusammenschluss in Biel sind gleichzeitig die neuen Büroräumlichkeiten in der Stadtmitte bezogen worden. Unseren rund 30 Mitarbeiterinnen und Mitarbeitern bieten sich attraktive Arbeitsplätze mit den neuesten EDV-Technologien. Eine optimale Voraussetzung für einen erfolgreichen Kundendienst.

\section{Was können wir für Sie tun?}

Als marktführendes Inkassounternehmen für Ärzte und Zahnärzte stellen wir Ihnen unsere jahrzehntelange Erfahrung im Inkasso von unbezahlten Honorarforderungen zur Verfügung. Wir regeln in Ihrem Interesse alle nötigen Vorabklärungen, beraten Sie individuell und besorgen auch die Verlustscheinverwaltung. Senden Sie uns Ihre Rechnungskopie oder die letzte Mahnung an Ihren Schuldner und wir erledigen den Rest für Sie. Zufriedene Kunden sind unsere beste Werbung.

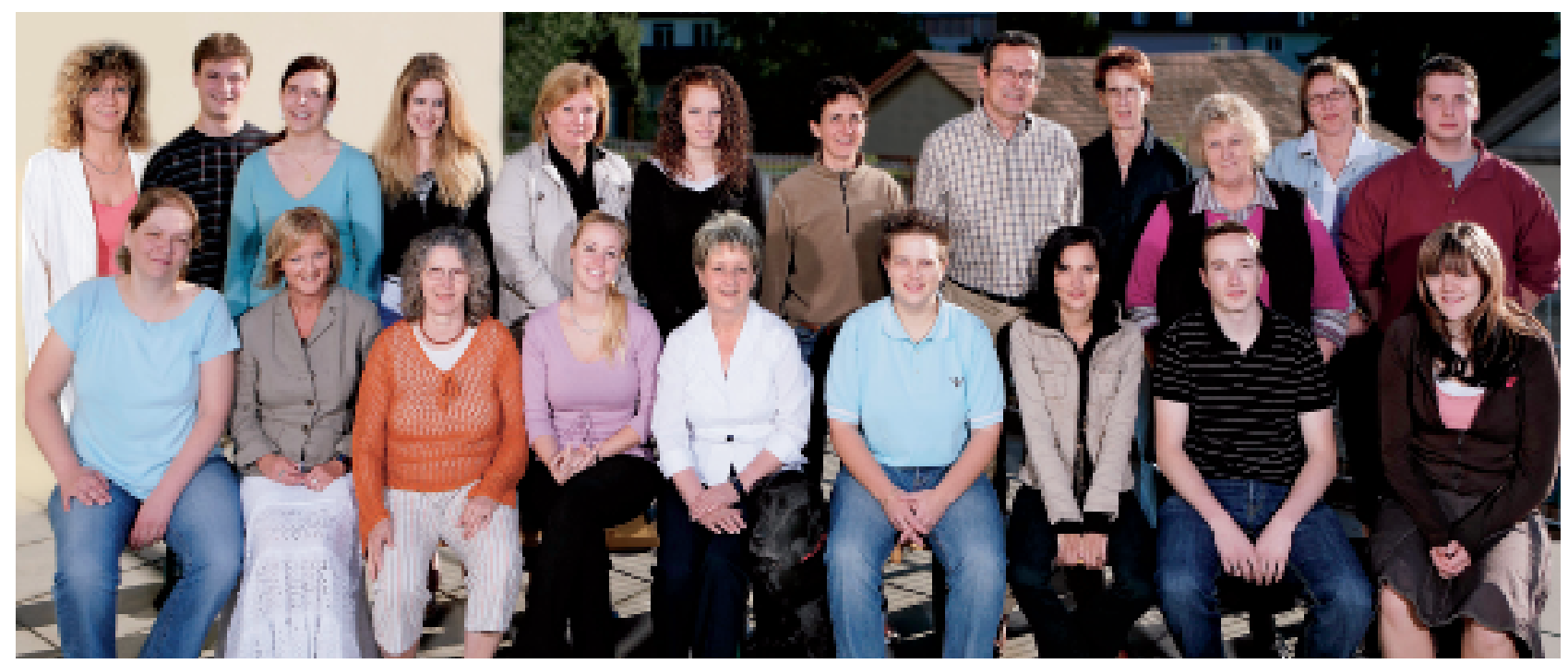

Team FMH Inkasso Services / INKAS

\section{Antworttalon}

Vorname / Name

Adresse

PLZ / Ort

Telefon Privat/Geschäft

Beste Zeit für einen Anruf

Ich wünsche eine persönliche Beratung.

Senden Sie mir Ihre Inkasso-Dokumentation.
FMH INKASSO

Inkassostelle Encath AG = Koordinationsstelle Postfach $800=2501$ Biel

Telefon 0323443969 a Fax 0323443966 mail@fmhininkasso.ch — www.fmhinkasso.ch 